\title{
Role of the cytomegalovirus major immediate early enhancer in acute infection and reactivation from latency
}

\author{
Mark F. Stinski · Hiroki Isomura
}

Received: 1 November 2007 / Published online: 19 December 2007

(c) Springer-Verlag 2007

\begin{abstract}
The cytomegalovirus (CMV) major immediate early (MIE) enhancer-containing promoter regulates the expression of the downstream MIE genes, which have critical roles in reactivation from latency and acute infection. The enhancer consists of binding sites for cellular transcription factors that are repeated multiple times. The primate and nonprimate CMV enhancers can substitute for one another. The enhancers are not functionally equivalent, but they do have overlapping activities. The CMV MIE enhancers are located between divergent promoters where the leftward genes are critical and essential for reactivation from latency and acute infection and the rightward gene is nonessential. The rightward transcription unit is controlled by an enhancer for murine CMV. In contrast, human CMV has a set of repressor elements that prevents enhancer effects on the rightward viral promoter. The human CMV enhancer that controls the leftward transcription unit has a distal component that is nonessential at high multiplicity of infection (MOI), but has a significant impact on the MIE gene expression at low MOI. The proximal enhancer influences directly the level of transcription of the MIE genes and contains an essential $\mathrm{Sp}-1$ site. The MIE promoter has a site adjacent to the transcription start site that is essential at the earliest stage of infection. The MIE enhancer-containing promoter responds to signal transduction events and to cellular differentiation. The role of the CMV MIE
\end{abstract}

\footnotetext{
M. F. Stinski ( $\square)$

Department of Microbiology, Carver College of Medicine, University of Iowa, Iowa City, IA 52242, USA

e-mail: mark-stinski@uiowa.edu

H. Isomura

Division of Virology, Aichi Cancer Center Research Institute,

1-1, Kanokoden, Chikusa-ku, Nagoya 464-8681, Japan
}

enhancer-containing promoter in acute infection and reactivation from latency are reviewed.

Keywords CMV enhancer - MIE promoter · Latency · Reactivation

\section{Introduction}

Cytomegaloviruses (CMVs) are members of the betaherpesviruses. These viruses cause disease in the host of origin and replicate slowly relative to the other herpesviruses. In humans, CMV causes disease in multiple organs such as lung, liver, retina, gastrointestinal tract, etc. CMV replicates in differentiated cells of the endoderm, mesoderm and ectoderm which include cell types such as macrophages, dendritic cells, colonic and retinal pigmented epithelial cells, endothelial cells, fibroblasts, smooth muscle cells, neuronal cells, glial cells, hepatocytes and trophoblasts [1-9]. In contrast, the virus fails to replicate in poorly differentiated cells such as progenitor cells of the bone marrow and monocytes of the blood. In these cells the virus is maintained in a latent state [10].

The inactivity of the viral major immediate early (MIE) promoter is characteristic of CMV latency [11, 12]. During latency, the viral genome is associated with enzymes such as histone deacetylase (HDAC) and methyltransferase that is typical of silenced chromatin. The viral major immediate early (MIE) promoter is associated with heterochromatin protein HP1, which selectively binds methylated histone [13].

The viral MIE enhancer-containing promoter can respond to cellular signal transduction events, which activate the MIE promoter and the expression of the downstream genes [14]. Early during productive infection, the viral genome is associated with histone acetylases that 
acetylate the histone and open-up the chromatin structure for transcription $[15,16]$. The viral MIE genes are located downstream of the MIE promoter and are necessary to initiate the productive replication cycle. The MIE gene products are rarely expressed during latency and are rate limiting for productive viral replication. The signal transduction events that activate the latent viral genome require further investigation. Our current data suggest that the MIE enhancercontaining promoter switches on or off depending on both cellular signal transduction events and the immune defenses of the host. With murine CMV, occasional MIE gene expression occurs during latency [17-19]. For example, the first gene downstream of the murine CMV MIE promoter, the ie1 gene, may be expressed without a return to productive infection. Even after the expression of the essential ie3 gene downstream of the MIE promoter, murine CMV does not necessarily enter a productive phase of infection [19]. In a nonpermissive monocytic cell type in cell culture, THP-1 cells, human CMV does not enter productive infection. Cellular differentiation is required for viral DNA synthesis and virus production [16]. Both the murine CMV studies in the host and the human CMV studies in cell culture indicate that cellular differentiation and the signal transduction events associated with cellular differentiation are necessary for viral reactivation from latency. Therefore, the CMV enhancer-containing promoter is a focal point to start the viral reactivation from latency, but the differentiation state of the cell determines the extent of viral gene expression and the production of infectious virus. Nevertheless, the CMV enhancer-containing promoter has one of the key roles for the genesis of disease by regulating viral latency and reactivation. This chapter will review the role of the CMV enhancer-containing promoter in acute infection and reactivation from latency.

\section{Cytomegalovirus enhancers}

Cytomegalovirus infections have been investigated in some detail in seven mammalian species. Figure 1 compares the
MIE enhancers of some of the primate and nonprimate CMVs. The CMV MIE enhancer elements characteristically have an array of cis-acting binding sites that are repetitive and bind cellular eukaryotic transcription factors. However, the arrangement and number of sites vary with the different species-specific viruses. The NF- $\kappa \mathrm{B}, \mathrm{CREB} /$ ATF, and AP-1 sites are commonly shared transcription factor-binding sites (Fig. 1) [20-30]. The primate CMV enhancers have more CREB/ATF sites and the nonprimate $\mathrm{CMV}$ s of mouse and rat have more AP-1 sites. Murine CMV and human CMV have RAR-RXR sites. Murine CMV has numerous NF- $\kappa$ B sites, but rat CMV does not. Human CMV has some unique far upstream sites like Elk1 , serum response factor, CBP, and gamma-interferon activating sites $[26,31]$. These structural variations presumably indicate evolutionary adaptations for more efficient viral replication in various cell types. The different cis-acting elements can act independently and cooperatively to attract and enhance RNA polymerase II transcription of the MIE genes [32-34]. It was inferred from transient transfection experiments that the CREB/ATF and NF- $\kappa \mathrm{B}$ sites were the key components of the human CMV enhancer [32]. Surprisingly, mutation of one type of site in the enhancer has no effect on transcription from the MIE promoter in the context of the remaining sites and viral infection of human fibroblast (HF) cells. For example, mutation of all the CREB/ATF sites or all the NF- $\kappa$ B sites has little to no effect on human CMV replication at high or low multiplicity of infection (MOI) [35, 36]. In addition, murine CMV with the enhancer substituted with the human CMV enhancer containing mutated NF- $\kappa \mathrm{B}$ binding sites replicated like wild type virus in mouse fibroblast cells [36].

Figure 2 demonstrates that there are multiple different binding sites for eukaryotic transcription factors in the human CMV genome and some sites are repeated multiple times. The multiple elements work together to promote transcription from the MIE promoter. It is possible that in the presence of the other multiple transcription factor binding sites of the entire enhancer, deletion of one type of site has little effect on replication in HF cell culture. Either the
Fig. 1 The enhancers of primate and nonprimate cytomegaloviruses. The known consensus binding sites of cellular transcription factors in the major immediate early enhancers are designated

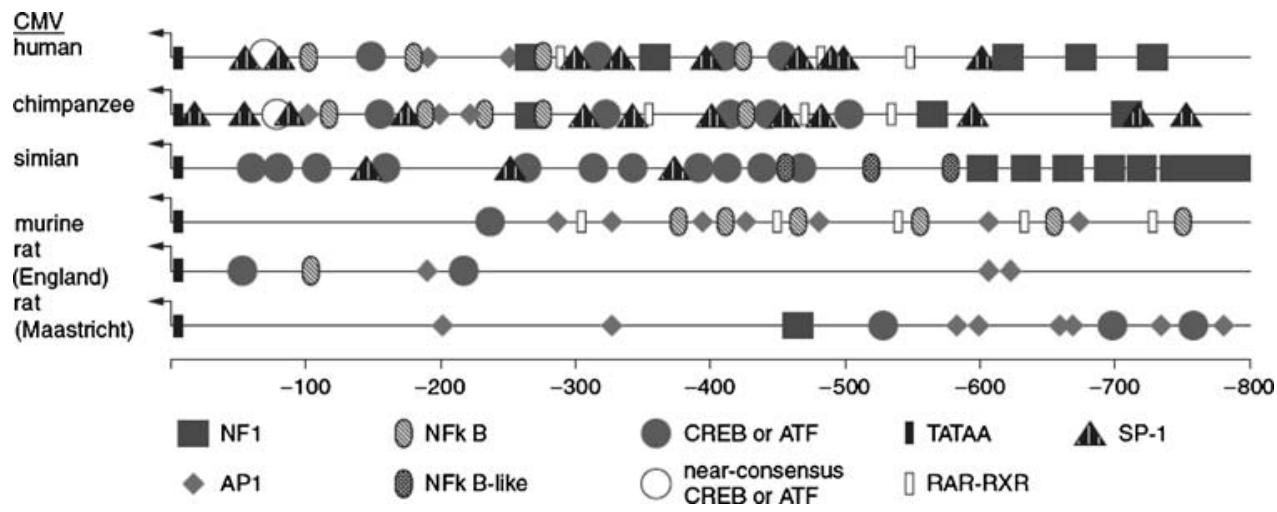




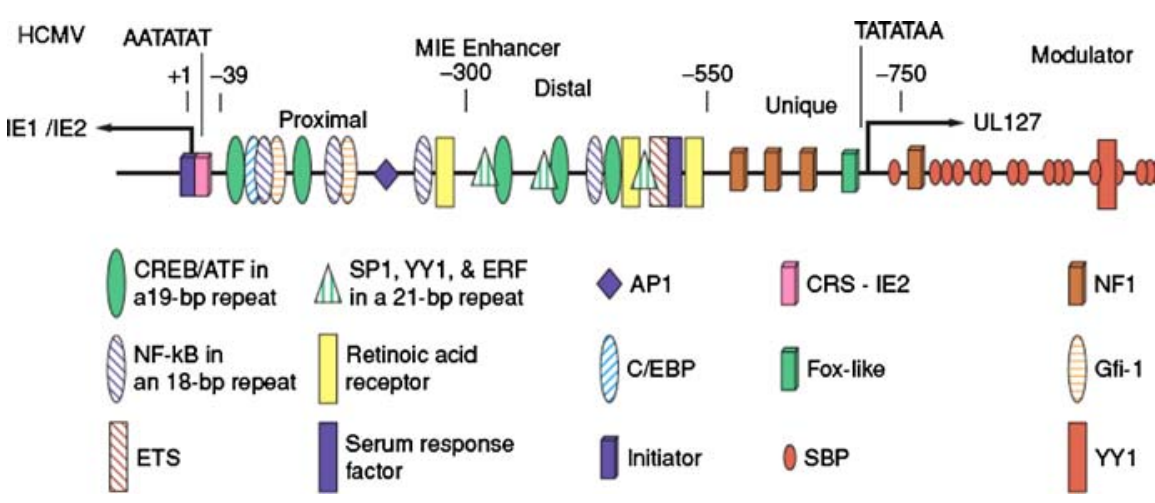

Fig. 2 The human cytomegalovirus major immediate early enhancer and divergent promoters. The viral genes and promoter/transcription start sites are designated by an arrow. The enhancer has two components that are proximal and distal. Between the distal enhancer and the
UL127 promoter is a unique region that binds transcriptional repressor proteins. Downstream of the UL127 promoter is a region referred to as the modulator. The transcription factor binding sites are designated

ward gene is on and leftward off or vice-versa [45]. The rightward gene appears to be expressed under tissue specific circumstances in the mouse, but the significance of this tissue specific expression is not understood [47]. Human CMV has a similar arrangement, except transcription of one gene of the pair is induced while transcription of the other is inhibited. There is a region between -740 and -550 that represses the rightward transcription of the UL127 gene at all times after infection of permissive HF cells referred to as the unique region (UR) (Fig. 2). The region was initially termed the UR because DNase I protection assays using nuclear extracts prepared from human cells demonstrated multiple interactions between unknown cellular proteins [48]. Deletion of the approximately 200-bp region between the UL127 TATA box and the MIE enhancer, results in rightward gene expression [49-51]. The UR is a complicated region that functions as a boundary domain or an insulator between the UL127 gene and the human CMV MIE enhancer. This region contains sites for the binding of cellular repressor proteins. The DNA binding proteins are transcriptional repressor proteins, some of which have been identified such as CCAAT displacement protein (CDP), special AT-rich sequence binding protein 1 (STAB-1), and pancreatic-duodenal homobox factor-1 (PDX-1) [52, 53]. It has been shown that SATB1 and CDP negatively regulate several viral and cellular genes through interaction with histone deacetylase and histone lysine methyltransferase [54-57]. CDP is a known transcriptional repressor protein that has effects on other viruses such as human papilloma virus and murine leukemia virus [58-61]. The UR of human CMV binds CDP, which represses expression from the human CMV UL127 promoter in transient transfection assays 4- to 6-fold. Down regulation of CDP in the cell by silencing RNA (siRNA) allows for higher expression from the UL127 promoter [52]. The UR also binds STAB1, but STAB1 did not independently repress the UL127 promoter ward and leftward genes stochastically, i.e. either the right- 
and the additive effect with CDP was marginal [52]. In transient transfection assays, PDX-1 repressed the MIE promoter [53]. There is a cis-acting site just upstream of the UL127 TATA box, referred to as the Fox-like site (Fig. 2) that represses transcription from the UL127 promoter as much as 80 to 100 -fold when in the context of the virus in infected HF cells [50]. The repressive function of the UR explains how the human CMV MIE enhancer can selectively activate expression of the MIE genes but not the UL127 gene during productive infection. In the context of the virus, the presence of the UR has no positive or negative effect on the MIE promoter in recombinant virus infected HF cells. The effect of the rightward gene in murine or human CMVs on viral replication or latency is presently an enigma.

There is also a large component that flanks the $3^{\prime}$ end of the UL127 ORF termed the modulator (Fig. 2). In transient transfection assays, the modulator augments transcriptional control from the MIE promoter [53, 62]. However, deletion of the modulator in recombinant viruses has no effect on human CMV replication in HF cells and in undifferentiated or differentiated monocytic THP-1 cells [63]. The effect of the modulator may either be redundant or have a role in cell types not tested to date. There is an A-T rich region with a dyad symmetry and multiple binding sites for cellular eukaryotic proteins such as YY1 and silencing binding protein (SBP) in the modulator (Fig. 2). Other binding sites such as ETS2-repressor factor (ERF) and Gfi-1 in the enhancer (Fig. 2) have been proposed to have a repressive effect on transcription from the MIE promoter in transient transfection assays, but this has not been demonstrated in recombinant viruses [64-67]. Removal of these sites by mutation in the viral genome did not relieve quiescence in cell culture model systems like the THP-1 and N-Tera 2 cells $[44,63,68]$.

\section{Substitution of CMV enhancers}

One approach to study the functions of the CMV enhancers has been to substitute the enhancer from one species with that from a different species. Enhancer substitution experiments demonstrated that the enhancers are not functionally equivalent but they do have overlapping activities. For example, the simian CMV enhancer can fully substitute for the human CMV enhancer, but replacing the human CMV enhancer with the murine CMV MIE enhancer results in diminished MIE gene expression, viral replication and the production of a small plaque phenotype in cell culture [69]. The rat CMV MIE enhancer substituted with the murine CMV enhancer replicated less efficiently in cell culture and reduced levels of virus were detected in the salivary glands of the infected rat [70]. Murine CMV enhancer substituted with the human CMV enhancer caused the virus to initiate infection less efficiently in the lung, spleen and adrenal glands of the mouse [71]. Lastly, while primate and nonprimate CMV enhancers can substitute for the human CMV enhancer, human herpesvirus 6 enhancer cannot (Isomura and Stinski, unpublished data). In general, the enhancer substitutions resulted in reduced viral replication efficiency, which indicates that the CMV enhancers have species specificity.

\section{The distal and proximal enhancers of human CMV}

The human CMV enhancer has a distal component between -550 and approximately -300 and a proximal component between approximately -300 and -39 relative to the transcription start site $(+1)$ of the MIE promoter. Without the distal enhancer, the recombinant virus replicates slowly at a low MOI and has a small plaque phenotype. The effect of deletion of the distal enhancer is detected only after infection at low MOI [72]. UV-inactivated human CMV at a high viral-particle to cell ratio can rescue the recombinant virus with the distal enhancer deletion. The murine CMV distal enhancer cannot substitute for the human CMV distal enhancer [69]. The distal and proximal enhancer components presumably interact because there is at least a 100fold reduction in virus production when the distal enhancer is deleted or substituted [69, 72].

The distal enhancer is composed of multiple cis-acting elements that function in $c i s$ and in either orientation (Fig. 2). Which cis-acting elements are most important for the function of the distal enhancer requires further investigation. There are sites at -510 and -380 that are gamma interferon activation sites (GAS). Recombinant viruses with these sites deleted or with point mutations replicated normally at high MOI and less efficiently at low MOI [31]. It is possible that signal transduction events that activate interferon also activate MIE gene expression. The open reading frames in the region can have stop codons inserted at -345 and -300 without any negative affect on distal enhancer function and MIE gene expression [33].

The proximal enhancer has cis-acting elements that directly affect transcription from the MIE promoter. Without the proximal enhancer, the recombinant virus cannot replicate. Successively larger $5^{\prime}$-end truncation of the proximal enhancer results in recombinant viruses that replicate slower and to lower titers. Enhancerless human CMV with just the TATA box containing promoter element does not replicate in HF cell culture [73]. The minimal enhancer element for human CMV replication in HF cell culture is an Sp- 1 binding site at either -75 or $-55[73,74]$. Viral replication is greatly diminished with one or two Sp-1 sites, and there is a characteristic minute plaque phenotype [74]. 
Human CMV infection induces an increase in Sp-1 DNA binding activity and the viral glycoproteins $\mathrm{gB}$ and $\mathrm{gH}$ in the viral envelope are responsible for this induction [14]. Sp-1 or Sp-3 transcription factors bind the GC boxes at -75 and -55 [74]. Sp-1 is reported to interact with TAF4 [75] and possibly factors binding to the initiator sequence (Inr) at the transcription start site [76]. In addition, Sp-1 is reported to interact with CREB/ATF [77, 78]. The Sp-1/Sp3 sites are between the upstream CREB/ATF sites and the downstream Inr and may bridge these components at the TATA box (Fig. 2). Sp-1 may also have an effect on the acetylation of histones at the MIE promoter. It is notable that the chimpanzee and simian CMVs also have Sp-1/Sp-3 binding sites in the proximal enhancer near the TATA box (Fig. 1). It is assumed that the cell type, the stage of cellular differentiation, and the activity of the various signal transduction pathways have an impact on both the distal and proximal enhancers.

When using infectious viral DNA in the absence of the distal enhancer and the virion envelope and tegument proteins, the NF-1, AP-1, Sp-1, CREB/ATF, and NF- $\kappa$ B cisacting sites in the proximal enhancer cumulatively affect transcription from the MIE promoter and recombinant virus replication (Lashmit et al., unpublished data). The NF- $\kappa \mathrm{B}$ sites as well as the AP-1 and NF-1 sites have a moderate effect in the presence of the two Sp-1 sites, but a single CREB/ATF site has a significant effect (Lashmit et al. unpublished data).

\section{The MIE promoter}

The human CMV promoter contains a TATA box between -28 and -22 , a cis-repression sequence (crs) between -13 and +1 , and an Inr between +1 and +7 [79]. When the crs is extensively mutated, recombinant virus cannot replicate even if the upstream proximal and distal enhancer elements are present. If the human CMV crs is substituted with the murine CMV crs, the recombinant virus replicates less efficiently (Isomura et al., unpublished data). In contrast, substitution with the simian crs, which has a sequence similar to the human crs, has no effect. When the crs is mutated at only two bases, -10 and -9 , there is 100 -fold less MIE transcription. In addition, there is a 20 -fold reduction in the splicing of the MIE precursor RNA [80]. These data indicate that the crs has an essential role in viral replication and may act as a positive element between the enhancer and the transcription start site in the early stages of MIE transcription. The crs may also act as a critical bridge between the transcription start site and the proximal enhancer for efficient MIE gene expression. An unknown cellular protein of approximately $150 \mathrm{kDa}$ binds to the MIE promoter between -15 and +7 [79]. When the viral MIE protein designated IE86 accumulates in the infected cell, it competes for binding to the region between -15 and +2 and represses transcription from the MIE promoter. Therefore, the crs element has the following two roles in early viral replication. (a) It plays a critical role in the early stages of transcription from the MIE promoter. (b) It prevents over expression of the MIE genes as the infection progresses.

\section{De-silencing the CMV enhancer containing promoter}

During latency, the CMV MIE promoter is associated with relatively high levels of HDACs, hypoacetylated histones and HP1 [13, 15]. An inhibitor of histone deacetylases, trichostatin A, will activate the MIE promoter and viral replication. Reactivation also occurs upon differentiation of CD34+ progenitor cells or monocytes into either dendritic cells or macrophages [15, 81, 82]. Allogeneic stimulation and proinflammatory cytokines are two events that have been linked to blood monocyte differentiation to macrophage or dendritic cells [82, 83]. In differentiated dendritic cells or macrophages, the MIE promoter is associated with relatively low levels of HDACs and higher levels of acetylated histones [13, 15, 81].

Two conditionally permissive cell lines have been used to investigate de-silencing of the viral genome in cell culture, the undifferentiated monocytic THP-1 cell or the neuroembryonic N-Tera-2 cell. These cells can be infected with human CMV and viral DNA can be found in the nucleus, but there is no viral MIE or early gene expression. In the undifferentiated THP- 1 cell, the MIE promoter is associated with histone modifications typical of silenced chromatin [84]. In the N-Tera-2 cells, some of the viral genomes can be found in a supercoiled structure which is considered to be representative of herpesvirus latent genomes [68].

The CMVs differ from the alphaherpesvirus, herpes simplex virus, and the gammaherpesviruses, Epstein Barr virus and Kaposi sarcoma virus, by requiring expression of both viral MIE proteins for reactivation from latency in cell culture or in the mouse $[16,18,19,85]$. The MIE CMV regulatory proteins will induce viral early gene expression. However, human CMV viral DNA synthesis and replication does not occur in the THP-1 cells without cellular differentiation [16]. Sporadic expression of the murine CMV MIE and early genes is not sufficient to signal viral reactivation and replication [19]. Because human CMV and murine CMV do not always replicate in cells expressing MIE or early viral proteins, cellular differentiation appears to be an important step in the viral reactivation process. While it has been assumed that MIE gene expression is the important rate-limiting step for CMV replication, cellular differentiation appears to be the major step for efficient viral reactivation. 
We know very little about the events necessary to activate the cell towards differentiation and the latent viral genome towards productive viral replication. Not all events leading to differentiation of the cell also lead to reactivation of the virus. Reactivation appears to be related to cytokine stimulation of the undifferentiated cell. Tumor necrosis factor alpha (TNF-alpha) activates the murine CMV MIE promoter through the NF- $\kappa \mathrm{B}$ and $\mathrm{AP}-1$ sites in the viral enhancer, but this is not enough to sustain viral reactivation in the mouse [86-88]. TNF-alpha plus allogeneic stimulation of $\mathrm{T}$ cells also induces murine CMV MIE promoter reactivation in the lungs or kidneys of the latently infected mouse [87, 89]. With human CMV, TNF-alpha and gamma released during the allogeneic stimulation of $\mathrm{T}$ cells contribute to activation of human CMV replication in monocytes from the blood [83]. While the MIE distal enhancer of human CMV contains two GAS sites for stimulation by gamma interferon as discussed above, quiescent human CMV in N-Tera-2 cells did not respond to gamma interferon [90]. In contrast, the quiescently viral infected cells did respond to stimulation of the cyclic-AMP pathway, which results in the activation of protein kinase pathways and phosphorylation of CREB/ATF. Inhibition of the protein kinase A pathway, but not the protein kinase $\mathrm{C}$ pathway, prevented activation of viral replication in the N-Tera2 cells. These results suggest that the CREB/ATF sites in the MIE enhancer of the latent viral genome might be one of the most responsive elements for reactivation of the latent virus. However, there are approximately 60 different stimuli for activation of CREB/ATF which include growth factor-, steroid hormone-, peptide-, cyclic nucleotide-, immune cell-, neurologic- and ion channel/intracellular $\mathrm{Ca}^{++}$signaling and effects by viral, bacterial, plant, phospholipid, and lipid components [91]. Saffer and Kalejta have proposed that the cellular protein Daxx mediates repression of the MIE promoter [92]. However, knockdown of hDaxx in nonpermissive undifferentiated cells did not permit human CMV MIE gene expression [93]. Which of the above are critical for reactivation from latency is currently not understood.

\section{Perspectives}

The CMV enhancers are responsive to cellular transcription factors. The mechanisms that trigger and sustain CMV reactivation from latency in vivo are largely unknown. A better appreciation of the nonvirion induced signal transduction events that activate transcription from the CMV MIE promoter during latency would shed additional light on the life cycle of the virus. The MIE enhancer-containing promoter may be first among multiple check points to control viral reactivation from latency. We also do not currently understand how the virus and the cell maintain the latent viral genome. Does the viral DNA replicate during cellular DNA replication? If so, where is the viral latent origin of replication? Does the virus use viral or cellular proteins to maintain the latent state? What is the relationship between cellular signal transduction events, cellular differentiation, and reactivation of virus from latency? Answers to these questions and others may lead to better strategies towards CMV disease prevention.

Acknowledgments We thank members of the Stinski lab and Jeffery Meier for critical review of this manuscript. Our work was supported by grant AI-13562 from the National Institutes of Health (M.F. S.) and by Grants-in-aid for Scientific Research on Priority Areas from the Ministry of Education, Science, Sports, Culture and Technology of Japan $(15390153,17659138$ and 16017322 to Tatsuya Tsurumi, and 17590429 to H.I.), Research on Health Sciences focusing on Drug Innovation (SH54412 to H.I.), and Grant-in-aid for Cancer Research (13-01 to H.I.) from the Ministry of Health, Labor and Welfare.

\section{References}

1. Fish KN, Depto AS, Moses AV, Britt W, Nelson JA (1995) Growth kinetics of human cytomegalovirus are altered in monocyte-derived macrophages. J Virol 69:3737-3743

2. Fish KN, Britt W, Nelson JA (1996) A novel mechanism for persistence of human cytomegalovirus in macrophages. J Virol 70:1855-1862

3. Hertel L, Lacaille VG, Strobl H, Mellins ED, Mocarski ES (2003) Susceptibility of immature and mature Langerhans cell-type dendritic cells to infection and immunomodulation by human cytomegalovirus. J Virol 77:7563-7574

4. Ibanez CE, Schrier R, Ghazal P, Wiley C, Nelson JA (1991) Human cytomegalovirus productively infects primary differentiated macrophages. J Virol 65(12):6581-6588

5. Maidji E, Percivalle E, Gerna G, Fisher S, Pereira L (2002) Transmission of human cytomegalovirus from infected uterine microvascular endothelial cells to differentiating placental cytotrophoblasts. Virology 304:53-69

6. Schmidbauer M, Budka H, Ulrich W, Ambros P (1989) Cytomegalovirus (CMV) disease of the brain in AIDS and connatal infection: a comparative study by histology, immunocytochemistry, and in situ DNA hybridization. Acta Neuropathol Berlin 79:286-293

7. Sinzger C, Muntefering H, Loning T, Stoss H, Placther B, Jahn G (1993) Cell types infected in human cytomegalovirus placentitis identified by immunohistochemical double staining. Virchows Arch A Pathol Anat Histopathol 4233:249-256

8. Sinzger C, Grefte A, Plachter B, Gouw ASH, Hauw The T, Jahn G (1995) Fibroblasts, epithelial cells, endothelial cells, and smooth muscle cells are the major targets of human cytomegalovirus infection in lung and gastrointestinal tissues. J Gen Virol 76:741750

9. Sinzger C, Jahn G (1996) Human cytomegalovirus cell tropisim and pathogenesis. Intervirology 39:302-319

10. Sinclair J, Sissons P (1996) Latent and persistent infections of monocytes and macrophages. Intervirology 39:293-301

11. Taylor-Wiedeman JA, Sissons JGP, Sinclair JH (1994) Induction of endogenous human cytomegalovirus gene expression after differentiation of monocytes from healthy carriers. J Virol 68:1597-1604

12. Slobedman B, Mocarski ES (1999) Quantitative analysis of latent human cytomegalovirus. J Virol 73:4806-4812 
13. Murphy J, Fischle W, Verdin E, Sinclair J (2002) Control of cytomegalovirus lytic gene expression by histone acetylation. EMBO J 21:1112-1120

14. Yurochko AD, Hwang E-S, Rasmussen L, Keay S, Pereira L, Huang E-S (1997) The human cytomegalovirus UL55 (gB) and UL75 $(\mathrm{gH})$ glycoprotein ligands initiate the rapid activation of $\mathrm{Sp} 1$ and NF-kB during infection. J Virol 71:5051-5059

15. Reeves MB, MacAry PA, Lehner PJ, Sissons JG, Sinclair JH (2005) Latency, chromatin remodeling, and reactivation of human cytomegalovirus in the dendritic cells of healthy carriers. Proc Natl Acad Sci USA 102(11):4140-4145

16. Yee L-F, Lin PL, Stinski MF (2007) Ectopic expression of HCMV IE72 and IE86 proteins is sufficient to induce early gene expression but not production of infectious virus in undifferentiated promonocytic THP-1 cells. Virology 363:174-188

17. Grzimek NKA, Dreis D, Schmalz S, Reddehase MJ (2001) Random, asynchronous, and asymmetic transcriptional activity of enhancer-flanking major immediate-early genes ie $1 / 3$ and ie 2 during murine cytomegalovirus latency in the lungs. J Virol 75:26922705

18. Kurz SK, Rapp M, Steffens H-P, Grzimek NKA, Schmalz S, Reddehase MJ (1999) Focal transcriptional activity of murine cytomegalovirus during latency in the lungs. J Virol 73:482-494

19. Kurz SK, Reddehase MJ (1999) Patchwork pattern of transcriptional reactivation in the lungs indicates sequential checkpoints in the transition from murine cytomegalovirus latency to recurrence. J Virol 73:8612-8622

20. Angulo A, Chandraratna RAS, LeBlanc JF, Ghazal P (1998) Ligand induction of retinoic acid receptors alters an acute infection by murine cytomegalovirus. J Virol 72:4589-4600

21. Angulo A, Suto C, Heyman RA, Ghazal P (1996) Characterization of the sequences of the human cytomegalovirus enhancer that mediate differential regulation by natural and synthetic retinoids. Mol Endocrinol 10:781-793

22. Beisser PS, Kaptein SJ, Beuken E, Bruggeman CA, Vink C (1998) The Maastricht strain and England strain of rat cytomegalovirus represent different betaherpesvirus species rather than strains. Virology 246:341-351

23. Thomsen DR, Stenberg RM, Goins WF, Stinski MF (1984) Promoter-regulatory region of the major immediate early gene of human cytomegalovirus. Proc Natl Acad Sci USA 81:659-663

24. Dorsch-Hasler K, Keil GM, Weber F, Schaffner JM, Koszinowski UH (1985) A long and complex enhancer activates transcription of the gene coding for the highly abundant immediate early mRNA in murine cytomegalovirus. Proc Natl Acad Sci USA 82:83258329

25. Chang YN, Crawford S, Stall J, Rawlins DR, Jeang KT, Hayward GS (1990) The palindromic series I repeats in the simian cytomegalovirus major immediate-early promoter behave as both strong basal enhancers and cyclic-AMP response elements. J Virol 64:264-277

26. Meier JL, Stinski MF (1996) Regulation of human cytomegalovirus immediate-early gene expression. Intervirology 39:331-342

27. Sandford GR, Burns WH (1996) Rat cytomegalovirus has a unique immediate early gene enhancer. Virology 222:310-317

28. Stinski MF (1999) Cytomegalovirus promoter for expression in mammalian cells. In: Ferandez JM, Hoeffler JP (eds) Gene expression systems: using nature for the art of expression. Academic Press, San Diego, pp 211-233

29. Vink C, Beuken E, Bruggeman CA (2000) Complete DNA sequence of the rat cytomegalovirus genome. J Virol 74:7656-7665

30. Davison AJ, Dolan A, Akter P, Addison C, Dargan DJ, Alcendor DJ et al (2003) The human cytomegalovirus genome revisited: comparison with the chimpanzee cytomegalovirus genome. J Gen Virol 84:17-28
31. Netterwald J, Yang S, Weijia W, Ghanny S, Cody M, Soteropoulos $\mathrm{P}$ et al (2005) Two gamma interferon-activated site-like elements in the human cytomegalovirus major immediate-early promoter/enhancer are important for viral replication. J Virol 79:5035-5046

32. Hunninghake GW, Monick MM, Liu B, Stinski MF (1989) The promoter-regulatory region of the major immediate-early gene of human cytomegalovirus responds to T-lymphocyte stimulation and contains functional cyclic AMP-response elements. J Virol 63:3026-3033

33. Meier JL, Keller MJ, McCoy JJ (2002) Requirement of multiple cis-acting elements in the human cytomegalovirus major immediate-early distal enhancer for viral gene expression and replication. J Virol 76:313-326

34. Meier JL, Stinski MF (2006) Major immediate-early enhancer and its gene products. In: Reddehase MJ (ed) Cytomegaloviruses molecular and immunology. Caister Academic Press, Norfolk, pp 151-166

35. Keller MJ, Wheeler DG, Cooper E, Meier JL (2003) Role of the human cytomegalovirus major immediate-early promoter's 19base-pair-repeat cyclic AMP-response element in acutely infected cells. J Virol 77:6666-6675

36. Benedict CA, Angulo A, Patterson G, Ha S, Huang H, Messerle M et al (2004) Neutrality of the canonical NF-kB-dependent pathway for human and murine cytomegalovirus transcription and replication in vitro. J Virol 78:741-750

37. Liu B, Stinski MF (1992) Human cytomegalovirus contains a tegument protein that enhances transcription from promoters with upstream ATF and AP-1 cis-acting elements. J Virol 66:4434-4444

38. Nogalski M, Podduturi JP, De Meritt IB, Milford LE, Yurochko AD (2007) The human cytomegalovirus virion possesses an activated casein kinase II that allows for the rapid phosphorylation of the inhibitor of NF-kappa B, I-kappa B alpha. J Virol 81:53055314

39. Cantrell SR, Bresnaha WA (2005) Interaction between the human cytomegalovirus UL82 gene product (pp71) and hDaxx regulates immediate-early gene expression and viral replication. J Virol 79:7792-7802

40. Cantrell SR, Bresnahan WA (2006) Human cytomegalovirus (HCMV) UL82 gene product (pp71) relieves hDaxx-mediated repression of HCMV replication. J Virol 80:6188-6191

41. Saffert RT, Kalejta RF (2006) Inactivating a cellular intrinsic immune defense mediated by Daxx is the mechanism through which the human cytomegalovirus pp71 protein stimulates viral immediate early gene expression. J Virol 80:3863-3871

42. Adachi N, Lieber MR (2002) Bidirectional gene organization: a common architectural feature of the human genome. Cell 109:807-809

43. Trinklein ND, Aldred SF, Hartman SJ, Schroeder DI, Otillar RP, Myers RM (2004) An abundance of bidirectional promoters in the human genome. Genome Res 14:62-66

44. Stinski MF, Meier JL (2007) Immediate-early CMV gene regulation and function. In: Arvin A et al. (eds) Human herpesviruses biology, therapy, and immunoprophylaxis. Cambridge University Press, London, pp 241-263

45. Simon CO, Kuhnapfel B, Reddehase MJ, Grzimek NKA (2007) Murine cytomegalovirus major immediate-early enhancer region operating as a genetic switch in bidirectional gene pair transcription. J Virol 81:7805-7810

46. Chatellard P, Pankiewics R, Meier E, Durrer L, Sauvage C, Imhof MO (2007) The IE2 promoter/enhancer region from mouse CMV provides high levels of therapeutic protein expression in mammalian cells. Biotech Bioeng 96:106-117

47. Reddehase MJ, Simon CO, Seckert CK, Lemmermann N, Grzimek NKA (2008) Murine model of cytomegalovirus latency and 
reactivation. In: Shenk T, Stinski MF (eds) Cytomegaloviruses. Springer, New York (in press)

48. Ghazal P, Lubon H, Reynolds-Kohler C, Hennighausen L, Nelson JA (1990) Interactions between cellular regulatory proteins and a unique sequence region in the human cytomegalovirus major immediate-early promoter. Virology 174:18-25

49. Angulo A, Kerry D, Huang H, Borst E-M, Razinsky A, Wu J et al (2000) Identification of a boundary domain adjacent to the potent human cytomegalovirus enhancer that represses transcription of the divergent UL127 promoter. J Virol 74:2826-2839

50. Lashmit PE, Lundquist CA, Meier JL, Stinski MF (2002) Cellular repressor inhibits human cytomegalovirus transcription from the UL127 promoter. J Virol 78:5113-5123

51. Lundquist CA, Meier JL, Stinski MF (1999) A strong negative transcriptional regulatory region between the human cytomegalovirus UL127 gene and the major immediate early enhancer. J Virol 73:9039-9052

52. Lee J, Klase Z, Gao X, Caldwell JS, Stinski MF, Kashanchi F et al (2007) Cellular homeoproteins, SATB1 and CDP, bind to the unique region between the human cytomegalovirus UL127 and major immediate-early genes. Virology 366:117-125

53. Chao S-H, Harada JN, Hyndman F, Gao X, Nelson CG, Chanda SK et al (2004) PDX1, a cellular homeoprotein, binds to and regulates the activity of human cytomegalovirus immediate early promoter. J Biol Chem 279:16111-16120

54. Nishio H, Walsh MJ (2004) CCAAT displacement protein/cut homolog recruits G9a histone lysine methyltransferase to repress transcription. Proc Natl Acad Sci USA 101:11257-11262

55. Li S, Moy L, Pittman N, Shue G, Aufiero B, Neufeld EJ et al (1999) Transcriptional repression of the cystic fibrosis transmembrane conductance regulator gene, mediated by CCAAT displacement protein/cut homolog, is associated with histone deacetylation. J Biol Chem 274:7803-7815

56. Snyder SR, Wang J, Waring JF, Ginder GD (2001) Identification of CCAAT displacement protein (CDP/cut) as a locus-specific repressor of major histocompatibility complex gene expression in human tumor cells. J Biol Chem 276:5323-5330

57. Yasui D, Miyano M, Cai S, Varga-Weisz P, Kohwi-Shigematsu T (2002) SATB1 targets chromatin remodelling to regulate genes over long distances. Nature 419:641-645

58. Ai W, Toussaint E, Roman A (1999) CCAAT displacement protein binds to and negatively regulates human papillomavirus type 6 E6, E7, and E1 promoters. J Virol 73:4220-4229

59. Pattison S, Skalnik DG, Roman A (1997) CCAAT displacement protein, a regulator of differentiation-specific gene expression, binds a negative regulatory element within the 5 ' end of the human papillomavirus type 6 long control region. J Virol 71:2013-2022

60. Zhu Q, Dudley JP (2002) CDP binding to multiple sites in the mouse mammary tumor virus long terminal repeat suppresses basal and glucocorticoid-induced transcription. J Virol 76:2168-2179

61. Zhu Q, Gregg K, Lozano M, Liu J, Dudley JP (2000) CDP is a repressor of mouse mammary tumor virus expression in the mammary gland. J Virol 74:6348-6357

62. Nelson JA, Reynolds-Kohler C, Smith B (1987) Negative and positive regulation by a short segment in the $5^{\prime}$-flanking region of the human cytomegalovirus major immediate-early gene. Mol Cell Biol 7:4125-4129

63. Meier JL, Stinski MF (1997) Effect of a modulator deletion on transcription of the human cytomegalovirus major immediate-early genes in infected undifferentiated and differentiated cells. J Virol 71:1246-1255

64. Bain M, Mendelson M, Sinclair J (2003) Ets-2 Repressor Factor (ERF) mediates repression of the human cytomegalovirus major immediate-early promoter in undifferentiated non-permissive cells. J Gen Virol 84:41-49
65. Huang TH, Oka T, Asai T, Okada T, Merrills BW, Gerston PN et al (1996) Repression by a differentiation-specific factor of the human cytomegalvirus enhancer. Nucleic Acids Res 24:16951701

66. Liu R, Baillie J, Sissons JGP, Sinclair JH (1994) The transcription factor YY1 binds to negative regulatory elements in the human cytomegalovirus major immediate early enhancer/promoter and mediates repression in nonpermissive cells. Nucleic Acids Res 22:2453-2459

67. Thrower AR, Bullock GC, Bissell JE, Stinski MF (1996) Regulation of a human cytomegalovirus immediate early gene (US3) by a silencer/enhancer combination. J Virol 70:91-100

68. Meier JL (2001) Reactivation of the human cytomegalovirus major immediate-early regulatory region and viral replication in embryonal NTera2 cells: role of trichostatin A, retinoic acid, and deletion of the 21-base-pair repeats and modulator. J Virol 75:1581-1593

69. Isomura H, Stinski MF (2003) Effect of substitution of the human cytomegalovirus enhancer or promoter with the murine cytomegalovirus enhancer or promoter on replication in human fibroblast. J Virol 77:3602-3614

70. Sandford GR, Brock LE, Voigt S, Forester CM, Burns WH (2001) Rat cytomegalovirus major immediate-early enhancer switching results in altered growth characteristics. J Virol 75:5076-5083

71. Grzimek NKA, Podlech J, Steffens H-P, Holtappels R, Schmalz S, Reddehase MJ (2000) In vivo replication of recombinant murine cytomegalovirus driven by the paralogous major immediate-early promoter-enhancer of human cytomegalovirus. J Virol 73:50435055

72. Meier JL, Pruessner JA (2000) The human cytomegalovirus major immediate-early distal enhancer region is required for efficient viral replication and immediate-early expression. J Virol 74:16021613

73. Isomura H, Tatsuya T, Stinski MF (2004) The role of the proximal enhancer of the major immediate early promoter in human cytomegalovirus replication. J Virol 78:12788-12799

74. Isomura H, Stinski MF, Kudoh A, Daikoku T, Shirata N, Tsurumi $\mathrm{T}$ (2005) Two Sp1/Sp3 binding sites in the major immediate-early proximal enhancer of human cytomegalovirus have a significant role in viral replication. J Virol 79:9597-9607

75. Saluja D, Vassallo MF, Tanese N (1998) Distinct subdomains of human TAFII130 are required for interactions with glutamine-rich transcriptional activators. Mol Cell Biol 18:5734-5743

76. Emami KH, Navarre WW, Smale ST (1995) Core promoter specificities of the Sp1 and VP16 transcriptional activation domains. Mol Cell Biol 15:5906-5916

77. Owen GI, Richer JK, Tung L, Takimoto G, Horwitz KB (1998) Progesterone regulates transcription of the p21(WAF1) cyclindependent kinase inhibitor gene through $\mathrm{Sp} 1$ and $\mathrm{CBP} / \mathrm{p} 300$. J Biol Chem 273:10696-10701

78. Tsai EY, Falvo JV, Tsytsykova AV, Barczak AK, Reimold AM, Glimcher LH et al (2000) A lipopolysaccharide-specific enhancer complex involving Ets, Elk-1, Sp1, and CREB binding protein and $\mathrm{p} 300$ is recruited to the tumor necrosis factor alpha promoter in vivo. Mol Cell Biol 20:6084-6094

79. Macias MP, Huang L, Lashmit PE, Stinski MF (1996) Cellular and viral protein binding to a cytomegalovirus promoter transcription initiation site: Effects on transcription. J Virol 70:3628-3635

80. Isomura H, Stinski MF, Kudoh A, Nakayama S, Murata T, Sato Y et al (2007) A cis-acting element between the TATA box and the transcription start site of the major immediate-early (MIE) promoter of human cytomegalovirus determines efficiency of viral replication. J Virol (in press)

81. Reeves MB, MacAry PA, Lehner PJ, Sissons JGP, Sinclair JH (2005) An in vitro model for the regulation of human cytomegalo- 
virus latency and reactivation in dendritic cells by chromatin remodeling. J Gen Virol 86:2949-2954

82. Soderberg-Naucler C, Streblow DN, Fish KN, Allan-Yorke J, Smith PP, Nelson JA (2001) Reactivation of latent human cytomegalovirus in CD14+ monocytes is differentiation dependent. $\mathrm{J}$ Virol 75:7543-7554

83. Soderberg-Naucler C, Fish KN, Nelson JA (1997) Interferon-gamma and tumor necrosis factor-alpha specifically induce formation of cytomegalovirus-permissive monocyte-derived macrophages that are refractory to the antiviral activity of these cytokines. J Clin Invest 100:3154-3163

84. Ioudinkova E, Arcangeletti MC, Rynditch A, De Conto F, Motta F, Covan S et al (2006) Control of human cytomegalovirus gene expression by differential histone modifications during lytic and latent infection of a monocytic cell line. Gene 384:120-128

85. Kurz S, Steffens H-P, Mayer A, Harris JR, Reddehase MJ (1997) Latency versus persistence or intermittent recurrences: evidence for a latent state of murine cytomegalovirus in the lungs. J Virol 71:2980-2987

86. Hummel M, Abecassis MI (2002) A model for reactivation of CMV from latency. J Clin Virol 25:S123-S136

87. Hummel M, Zheng Z, Yan S, Deplaen I, Golia P, Varghese T et al (2001) Allogeneic transplantation induces expression of cytomeg- alovirus immediate-early genes in vivo: a model for reactivation from latency. J Virol 75:4814-4822

88. Simon CO, Seckert CK, Dreis D, Reddehase MJ, Grzimek NKA (2005) Role of tumor necrosis factor alpha in murine cytomegalovirus transcriptional reactivation in latently infected lungs. J Virol 79:326-340

89. Cook CH, Trgovcich J, Zimmerman PD, Zhang Y, Sedmak DD (2006) Lipopolysaccharide, tumor necrosis factor alpha, or interleukin-1b triggers reactivation of latent cytomegalovirus in immunocompetent mice. J Virol 80:9151-9158

90. Keller MJ, Wu AW, Andrews JI, McGonagill PW, Tibesar EE, Meier JL (2007) Reversal of human cytomegalovirus major immediate-early enhancer/promoter silencing in quiescently infected cells via the cyclic AMP signaling pathway. J Virol 81:6669-6681

91. Johannessen M, Delghandi MP, Moens U (2004) What turns CREB on? Cell. Signalling 16:1211-1227

92. Saffert RT, Kalejta RF (2007) Human cytomegalovirus gene expression is silenced by Daxx-mediated intrinsic immune defense in model latent infections established in vitro. $\mathrm{J}$ Virol 81(17):9109-9120

93. Groves I, Sinclair J (2007) Knockdown of hDaxx in normally nonpermissive undifferentiated cells does not permit human cytomegalovirus immediate-early gene expression. J Gen Virol 88:2935-2940 